\title{
Redistribution of trace gases by convective clouds - mixed-phase processes
}

\author{
Y. Yin, K. S. Carslaw, and D. J. Parker \\ Institute for Atmospheric Science, School of the Environment, University of Leeds, Leeds, UK
}

Received: 10 May 2002 - Published in Atmos. Chem. Phys. Discuss.: 24 June 2002

Revised: 18 October 2002 - Accepted: 21 October 2002 - Published: 29 October 2002

\begin{abstract}
The efficiency of gas transport to the free and upper troposphere in convective clouds is investigated in an axisymmetric dynamic cloud model with detailed microphysics. In particular, we examine the sensitivity of gas transport to the treatment of gas uptake by different ice hydrometeors. Two parameters are used to describe this uptake. The gas retention coefficient defines the fraction of dissolved gas that is retained in an ice particle upon freezing, which includes also the riming process. We also define a gas burial efficiency defining the amount of gas entrapped in ice crystals growing by vapour diffusion. Model calculations are performed for continental and maritime clouds using a complete range of gas solubilities, retention coefficients and burial efficiencies. The results show that the magnitude of the gas retention coefficient is much more important for gas transport in maritime clouds than in continental clouds. The cause of this difference lies in the different microphysical processes dominating the formation and evolution of hydrometeors in the two cloud types. For highly soluble gases, the amount of gas transported to the free troposphere in maritime clouds falls approximately linearly by a factor of 12 as the retention coefficient is varied between 0 and 1 . Gas transport is relatively insensitive to the magnitude of the gas burial efficiency. However, the burial efficiency strongly controls the concentration of trace gases inside anvil ice crystals, which subsequently form cirrus clouds.
\end{abstract}

\section{Introduction}

Convective cloud transport is a primary mechanism for moving trace gas species from the boundary layer to the free troposphere or even lower stratosphere (e.g. Chatfield and Crutzen, 1984; Dickerson et al., 1987; Prather and Jacob, 1997; Barth et al., 2001; Yin et al., 2001). In our previous

Correspondence to: Y. Yin (yan@env.leeds.ac.uk) paper (Yin et al., 2001) we developed a spectral treatment of gas scavenging within a two-dimensional cloud model to investigate trace gas vertical redistribution in precipitating continental and maritime clouds without ice formation. The simulations revealed a clear pattern of behaviour depending on gas solubility. The transport of low solubility gases (with effective Henry's law constants $H^{*}<10^{3} \mathrm{~mol} \mathrm{dm}^{-3} \mathrm{~atm}^{-1}$ ) was found to be essentially identical to that of an insoluble tracer. All highly soluble gases $\left(H^{*}>10^{6} \mathrm{~mol} \mathrm{dm}^{-3} \mathrm{~atm}^{-1}\right)$ were also found to behave in a nearly identical way to each other, independent of their solubility. On the other hand, the transport of moderately soluble gases $\left(H^{*}\right.$ between $10^{3}$ and $10^{6} \mathrm{~mol} \mathrm{dm}^{-3} \mathrm{~atm}^{-1}$ ) depends on the precise value of $H^{*}$.

In this study we extend the treatment of gas scavenging to include ice-phase particles with special attention being paid to the mass transfer between different hydrometeor types induced by drop-ice interactions. Besides dissolution of the gas into liquid drops, scavenging of a gas in ice- or mixed-phase clouds involves two additional processes: the direct uptake of the gas by ice particles and transfer of dissolved gas between the aqueous phase and ice phase due to freezing and riming.

Extensive laboratory and field studies have been conducted by others to investigate the uptake by ice particles of some chemical species found in clouds, including $\mathrm{HNO}_{3}$, $\mathrm{SO}_{2}, \mathrm{HCl}, \mathrm{HBr}, \mathrm{H}_{2} \mathrm{O}_{2}$ (e.g. Sommerfeld and Lamb, 1986; Clapsaddle and Lamb, 1989; Valdez et al., 1989; Mitra et al., 1990; Conklin et al., 1993; Conklin and Bales, 1993; Diehl et al., 1995; Santachiara et al., 1995; Zondlo et al., 1997; Diehl et al., 1998; Hudson et al., 2001; Clegg and Abbatt, 2001). These studies show that the gas uptake depends on many factors, including partial pressure, temperature, surface acidity, and even whether the ice phase is growing or not (e.g. Diehl et al., 1995; Clegg and Abbatt, 2001). However, due to the lack of a theoretical framework to properly describe the contributions from these factors, it is difficult to include this process into cloud chemistry models.

(C) European Geosciences Union 2002 
In an idealized simulation using a global chemical transport model, Crutzen and Lawrence (2000) investigated the sensitivity of trace gas removal by the ice particles by introducing ice-phase Henry's Law constants $H_{i, x}$ (' $i$ ' stands for “ice”), which were assumed to be proportional to the gas-liquid solubility $\left(H_{i, x}=r_{i} H_{x}^{*}\right.$, where $\left.r_{i} \leq 1\right)$, and found that inclusion of ice uptake essentially extended the vertical region of gas scavenging.

During formation and growth of ice phase hydrometeors via freezing or riming, trace chemical species originally in the aqueous phase may be excluded or retained in the growing ice phase particles. The retention coefficient $\left(R_{c}\right.$ in this study), which is the ratio of the concentration of solute retained in the ice phase to that in the parent liquid phase, has been measured by many investigators (e.g. Lamb et al., 1987; Iribarne et al., 1990; Snider et al., 1992; Santachiara et al., 1995). $R_{c}$ values range from 0.01 to unity, depending on the trace species, but sometimes different $R_{c}$ values were also reported for the same species. For example, Lamb et al. (1987) observed that the entrapped fraction of $\mathrm{SO}_{2}$ was strongly temperature dependent and ranged from about 0.01 near $0^{\circ} \mathrm{C}$ to more than 0.12 at $-20^{\circ} \mathrm{C}$. On the other hand, Iribarne et al. (1990) reported an average value $R_{c}=0.62$ independent of temperature and $\mathrm{SO}_{2}$ concentration. In another experiment for highly soluble gases such as $\mathrm{HCl}, \mathrm{HNO}_{3}$, and $\mathrm{H}_{2} \mathrm{O}_{2}$, Iribarne and Pyshnov (1990) measured $R_{c}$ of about unity, but a value of only 0.3 was observed for $\mathrm{H}_{2} \mathrm{O}_{2}$ by Snider et al. (1992) in natural clouds.

Voisin et al. (2000) performed in-cloud field measurements to study the scavenging processes of acidic gases and ammonia in mixed-phase clouds. These authors found that strong acids are well retained in rime ice. For these species, riming is the main process that determines the composition of the snowflake. At lower solubility, the authors found that riming is still important but gas uptake during the growth of snowflakes cannot be neglected.

Mari et al. (2000) examined the transport and scavenging of several gas species, including $\mathrm{CO}, \mathrm{CH}_{3} \mathrm{OOH}, \mathrm{CH}_{2} \mathrm{O}$, $\mathrm{H}_{2} \mathrm{O}_{2}, \mathrm{HNO}_{3}$, and $\mathrm{SO}_{2}$, in tropical deep convection, using a one-dimensional entraining/detraining plume model. They noticed that while both $\mathrm{HNO}_{3}$ and $\mathrm{H}_{2} \mathrm{O}_{2}$ were efficiently scavenged in the lower (warm) part of the cloud, $\mathrm{H}_{2} \mathrm{O}_{2}$ was released as the cloud froze due to the low retention efficiency during riming.

In a numerical simulation of the fate of soluble gases in mid-latitude convection, Barth et al. (2001) considered two extreme cases for the interaction of the gas with cloud hydrometeors. The first case assumed that the dissolved gas in the cloud water or rain completely degassed when the parent hydrometeor was converted to ice-phase hydrometeors. The second case assumed that the dissolved tracer was retained in the ice-phase particles. They found that when soluble tracers were degassed, both low and high solubility tracers were transported to the upper troposphere. When tracers were retained in ice hydrometeors, the highly soluble tracers were not ultimately transported to the upper troposphere, but instead were precipitated out of the upper troposphere by snow and hail.

In this study, numerical simulations are performed to understand how gas transport in mixed-phase precipitating clouds is influenced by hydrometeor transformations and uptake of gases by ice-phase particles. For this purpose, the spectral treatment of gas scavenging in Yin et al. (2001) has been extended to include ice-phase hydrometeors and incorporated into an axisymmetric non-hydrostatic cloud model with detailed microphysics. As in our previous study, we do not restrict our simulations to specific gases under specific conditions. Rather, we examine clouds formed on both continental and maritime aerosol spectra and use a complete range of gas solubilities, retention coefficients and uptake efficiencies on to ice particles. We take this approach in order to understand the overall importance of the ice phase in gas transport and, in particular, the implications of gas-ice interaction parameters being poorly constrained by experiments and theory.

A brief description of the model is given in Sect. 2, followed by the initial conditions for the simulations and design of the numerical experiments in Sect. 3. In Sect. 4, the main results are presented, and discussions and summaries are given in Sect. 5 .

\section{Model description}

\subsection{The model dynamics and microphysics}

The dynamic framework and microphysical processes of an axisymmetric nonhydrostatic anelastic convective cloud model developed by Reisin et al. (1996) were used in this study and will be only briefly described here. The improved calculation of some of the microphysical processes such as drop nucleation, and immersion freezing of drops, presented by Yin et al. (2000), were also introduced. In the model, a set of dynamic equations were solved for the vertical and radial velocity, the pressure perturbation, the virtual potential temperature perturbation, the specific humidity perturbation, the specific concentration of aerosols, the specific number and mass for each type of cloud particles in a spectral bin, and concentration of activated ice nuclei.

The warm microphysical processes included are: nucleation of drops, condensation and evaporation, collisioncoalescence, and binary breakup (Low and List kernel). The ice microphysical processes included are: ice nucleation (deposition, condensation-freezing, contact nucleation, and immersion freezing), ice multiplication, deposition and sublimation of ice, ice-ice and ice-drop interactions, melting of ice particles, and sedimentation of drops and ice particles. All these microphysical processes are formulated and solved using the method of Multi-Moments (Tzivion et al., 1987; Reisin et al., 1996). Four species of hydrometeor are 


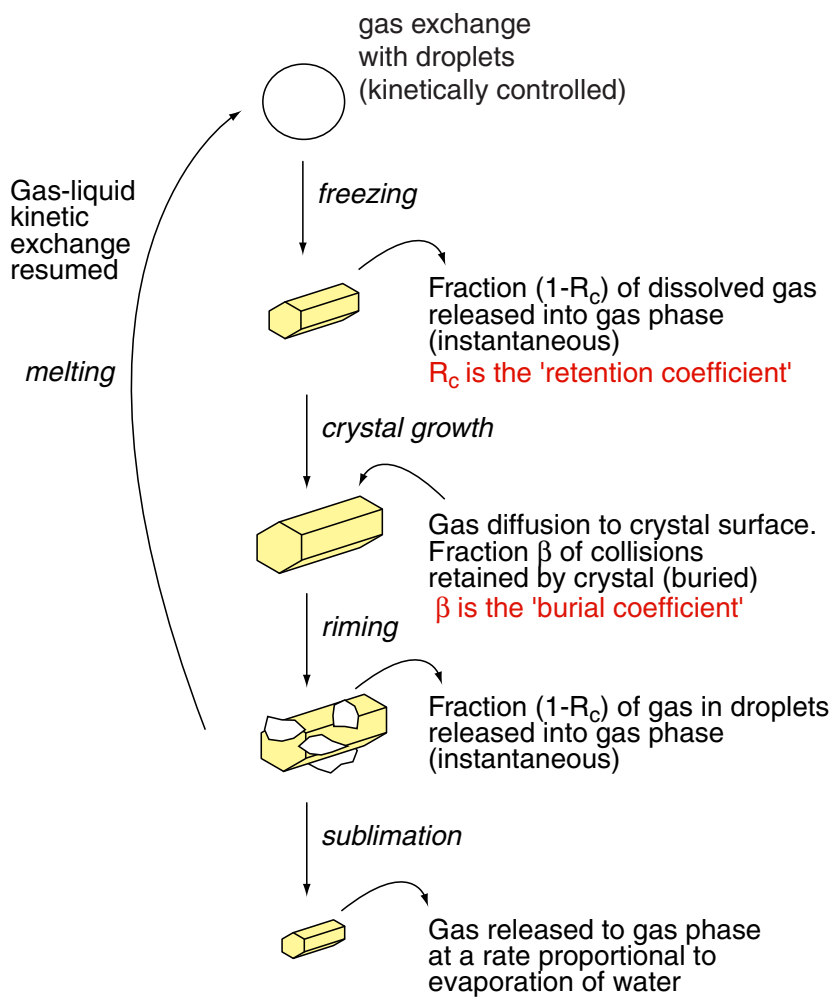

Fig. 1. Schematic of gas interaction with different hydrometeors used in this study.

considered: drops, ice crystals, graupel particles and aggregates (snowflakes). The density of the graupel is assumed to be $0.4 \mathrm{~g} \mathrm{~cm}^{-3}$, while the ice crystal density varies from $0.9 \mathrm{~g} \mathrm{~cm}^{-3}$ for the smallest particles, down to $0.45 \mathrm{~g} \mathrm{~cm}^{-3}$ for the biggest. The density for the aggregates is fixed at $0.2 \mathrm{~g} \mathrm{~cm}^{-3}$. Each particle species is divided into 34 bins with mass doubling for adjacent bins $\left(m_{k+1}=2 m_{k}, k=\right.$ $1, \cdots 34)$. The masses at the beginning of the first bin and the end of last bin for both liquid and solid phases are $0.1598 \times 10^{-13}$ and $0.17468 \times 10^{-3} \mathrm{~kg}$, which correspond to drop diameters of 3.125 and $8063 \mu \mathrm{m}$, and ice particle diameters of 3.23754 and $8540 \mu \mathrm{m}$, respectively. Aerosols are divided into 67 bins with the minimum radius of $0.0041 \mu \mathrm{m}$. The domain in the model is $12 \mathrm{~km}$ in the vertical and $6 \mathrm{~km}$ in the radial direction. The grid size is $150 \mathrm{~m}$ and $300 \mathrm{~m}$, respectively, in the radial and vertical direction. A time step of $2.5 \mathrm{~s}$ is used for condensation/evaporation of drops or deposition/sublimation of ice particles, $0.1 \mathrm{~s}$ for gas absorption, and $5 \mathrm{~s}$ for all other processes.

To simulate the evolution of trace gases in the air and in hydrometeors, the dynamic and microphysical equations are also applied to the mixing ratio of a gas species $i$ in the air, $M_{a, i}$, and the mixing ratio in hydrometeors, $M_{h, i}$. These equations are given as

$$
\frac{\partial M_{a, i}}{\partial t}=F_{q}\left(M_{a, i}\right)-D\left(M_{a, i}\right)
$$

$$
+\left(\frac{\partial M_{a, i}}{\partial t}\right)_{\text {uptake }}+\left(\frac{\partial M_{a, i}}{\partial t}\right)_{\text {micro }}
$$

and

$$
\begin{aligned}
\frac{\partial M_{h, i, k}}{\partial t} & =F_{q}\left(M_{h, i, k}\right)-D\left(M_{h, i, k}\right) \\
& +\left(\frac{\partial M_{h, i, k}}{\partial t}\right)_{\text {uptake }}+\left(\frac{\partial M_{h, i, k}}{\partial t}\right)_{\text {micro }}
\end{aligned}
$$

where the subscript $k$ denotes the particle spectral bin number. The terms $D$ and $F_{q}$ represent the advective and turbulent transfer operators. The variation of these functions with location is implied. Also, the terms with subscripts "uptake" and "micro" represent mass transfer of chemical species between the gas phase and condensed phase due to uptake of gases by drops and ice particles, and that between different particle species due to microphysical processes.

\subsection{Mass transfer between gas and hydrometeors}

\subsubsection{Gas interaction with droplets}

The rate of mass transfer between gas phase and aqueous phase for chemical species $i$ and a group of aqueous drops with radius of $r$ and number concentration of $N_{r}$ (per mole of air) is calculated using the following kinetic equation

$\frac{d M_{d, i, r}}{d t}=\frac{3 \eta D_{g, i} N_{S h, i}}{R T r^{2}}\left(V_{r} N_{r} P_{i}-\frac{M_{d, i, r}}{H_{i}^{*}}\right)$,

where $M_{d, i, r}$ is the molar mixing ratio with respect to air of gas species $i$ inside drops with radius $r, H^{*}$ is the effective Henry's law constant of species $i, R$ is the universal gas constant, $T$ is the temperature, $D_{g, i}$ is the diffusivity of gas species $i$ in air, $V_{r}$ is the volume of drops with radius $r, P_{i}$ is the partial pressure of gas species $i$ in the environment, $N_{S h, i}$ is the mass ventilation coefficient (Sherwood number), and $\eta$ is a factor to account for the free-molecular effect on the mass transfer rate. This equation has the analytical solution

$M_{d, i, \bar{r}_{k}}(\tau+\Delta \tau)=A(\tau)+\left[M_{d, i, \bar{r}_{k}}(\tau)-A(\tau)\right] \exp (B \Delta \tau),(4)$

where $\Delta \tau$ is the time step $(0.1 \mathrm{~s})$ for gas dissolution, and

$$
A(\tau)=\frac{4}{3} \pi \bar{r}_{k}^{3} N_{k} P_{i}(\tau) H_{i}^{*}, \quad B=-\frac{3 D_{g, i} N_{S h, i} \eta}{\bar{r}_{k}^{2} R T H_{i}^{*}} .
$$

\subsubsection{Freezing of droplets and gas retention}

The model treatment of gas interaction with ice hydrometeors is shown in Fig. 1. When droplets freeze, a fraction $R_{c}$ of the gas is retained by the ice crystal and $\left(1-R_{c}\right)$ released to the gas phase. The partitioning of the gas between the gas and ice phase is assumed to be instantaneous. The gas sequestered by the ice crystal is assumed to be fully retained; that is, no equilibrium is set up between the concentration of gas in the crystal and the gas phase. This is a valid assumption due to the slow diffusion of the gas through the crystal. 

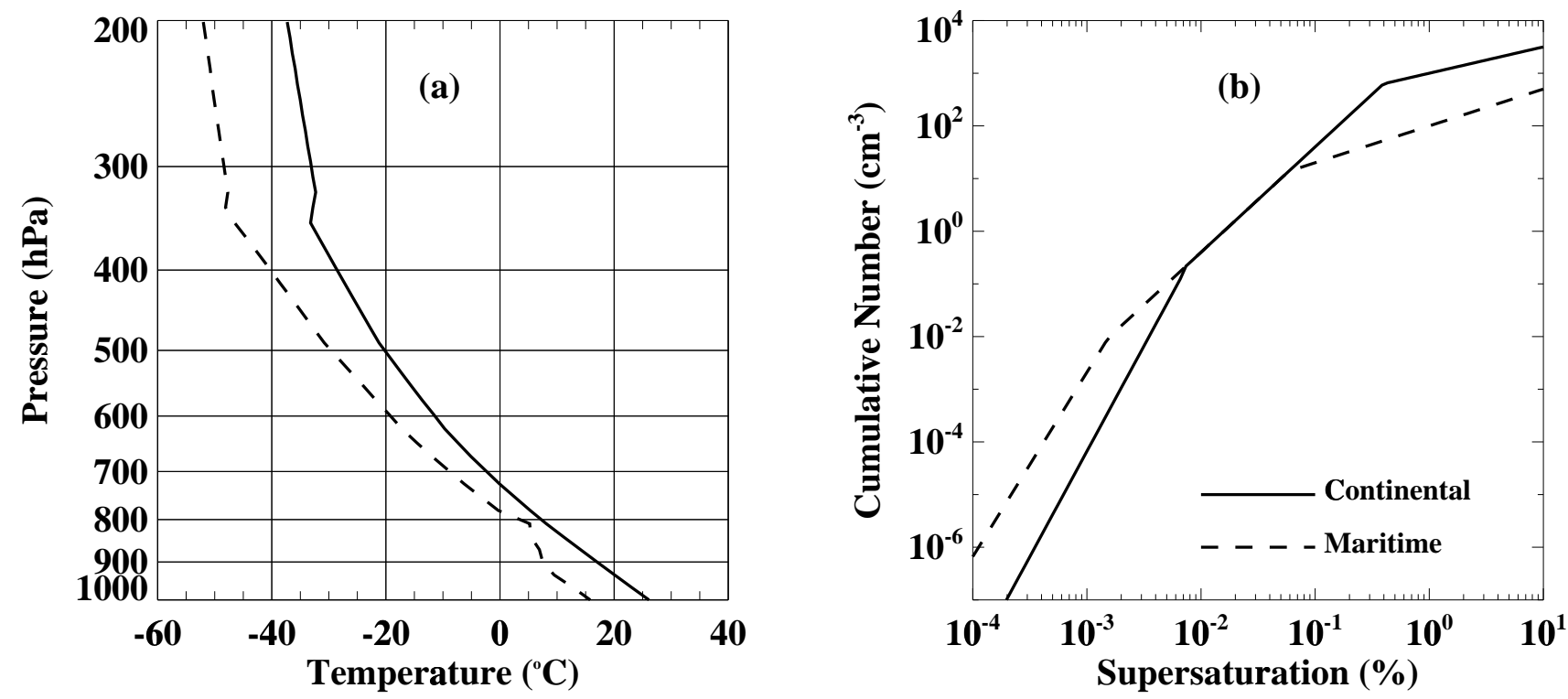

Fig. 2. (a) Initial profiles of temperature (solid line) and dew point temperature (dashed line), and (b) CCN spectra used in the present work.

In this study, we perform five modeling simulations, each for clouds formed on continental and maritime aerosol spectra, with the gas retention coefficient, $R_{c}$, ranging from 0.0 to 1.0. The extreme case with retention coefficient equal to 0.0 means that the dissolved gas is transferred completely to the gas phase when a hydrometeor freezes. In the other extreme case of $R_{c}=1$, the dissolved gas mass is retained fully by the resultant ice hydrometeor.

\subsubsection{Gas scavenging during growth of ice crystals by vapour diffusion}

Trace species can also be transferred into ice hydrometeors from the gas phase. Ice crystals in a convective cloud are often growing rapidly, so the concept of an equilibrium coverage of the ice surface with a trace gas is not appropriate. Rather, it is likely that trace gas molecules transiently attached to the ice surface will quickly become buried by several monolayers of deposited vapour or by rimed droplets, and will be released to the gas phase only when the ice particle evaporates again.

Given the uncertainty in the physical processes that lead to gas uptake in this way, we have included in the model a single parameter, the burial coefficient $(\beta)$, that describes different efficiencies of gas trapping in growing ice hydrometeors. A value of $\beta=1$ assumes that all trace gas molecules that diffuse to the growing crystal surface become buried, while a lower value of $\beta$ implies that a fraction of the gas molecules that strike the crystal become buried and a fraction $(1-\beta)$ remain in the gas phase.

The practical implementation of the burial coefficient in the model is simply to vary $\alpha_{w}$, the mass accommodation coefficient, which appears in the equation describing the flux of trace gas to the ice surface. This is a simplification, and there may be circumstances where in reality $\beta \neq \alpha_{w}$. The burial coefficient is likely to be close to 1 for species that adsorb strongly on the surface of a static ice surface. Strongly adsorbing molecules have a long residence time on the surface before desorption, so are likely to suffer burial by water molecules or rime whenever ice hydrometeors are growing. Strongly adsorbing molecules are likely to have high burial coefficients and high accommodation coefficients. Gases having a weak interaction with the ice surface and which desorb at a rate comparable to the deposition rate of water molecules are likely to have low burial coefficients and low accommodation coefficients. However, even a weakly adsorbing molecule with a low accommodation coefficient on a static ice surface could have a large burial coefficient in cases where the riming rate or deposition rate of water molecules is very high. Conversely, highly adsorbing molecules could have low burial efficiencies in cases where ice crystals are growing very slowly, such as in the anvil cirrus.

As a sensitivity test we vary the fraction of molecules that become permanently buried by varying $\beta$ between 0 and 1 . We note that further experimental work needs to be done in order to parameterise gas uptake for a wide range of ice particle growth rates, strengths of gas interaction with static ice surfaces, ice forms, etc.

\subsubsection{Riming}

Riming causes ice crystals to grow by accretion and freezing of supercooled water droplets. When riming occurs, the fraction $R_{c}$ of the chemical species in the accreting droplet is retained in the rimed ice particle and a fraction $\left(1-R_{c}\right)$ is released to the gas phase. 


\subsubsection{Sublimation and melting}

When ice hydrometeors sublime we assume that the buried trace gas is released to the gas phase at a rate proportional to the mass of water evaporated. The gas is assumed to be uniformly distributed through the particle, thus we do not retain information on the radial distribution of the buried gas.

Upon melting, the buried gas mass is retained in the new droplet and used to calculate a liquid phase concentration. Gas-liquid mass transfer is then calculated as for other droplets.

\section{Initial conditions and numerical experiments}

\subsection{Initial conditions}

Numerical experiments were performed for continental and maritime conditions. For both cases an artificial thermodynamic profile representative of typical conditions was used. The profile produces a cloud with a base at $8-10^{\circ} \mathrm{C}(1.5-$ $1.8 \mathrm{~km})$ and a top at $-25^{\circ} \mathrm{C}(7.0 \mathrm{~km})$. For initialization, a warm bubble that produced a $2^{\circ} \mathrm{C}$ perturbation was applied for one time step at $t=0$ in a region with radial distance of $450 \mathrm{~m}$, at a height of $600 \mathrm{~m}$. Therefore, the cloud simulated in this study may be representative of an isolated convective cloud or one of the growing cells in a more complicated convective cloud system.

The number concentration of aerosols large enough to act as cloud condensation nuclei $(\mathrm{CCN})$ distinguishes the maritime and continental clouds. The $\mathrm{CCN}$ are assumed to be composed of ammonium sulfate, regardless of size, and the CCN concentrations are assumed to decrease exponentially with altitude with a scale height of $2.5 \mathrm{~km}$ (according to Pruppacher and Klett, 1997). The initial profiles of temperature, dew point temperature, and CCN spectra are shown in Fig. 2.

Because the main purpose of these simulations is to estimate to what extent the gases from the boundary layer can be transported to the free atmosphere and upper troposphere, the initial trace gas mixing ratio was arbitrarily assumed to be 1 ppbv and to be homogeneously distributed in the boundary layer, with a height of $1.5 \mathrm{~km}$.

\subsection{Numerical experiments}

Numerical experiments were conducted to test the sensitivity of gas transport to the value of retention coefficient $\left(R_{c}\right.$ $=0,0.25,0.5,0.75$, and 1.0) and gas burial efficiency in growing ice crystals $(\beta=0,0.01,0.1$, and 1.0$)$. The experiments were repeated for the maritime and continental cloud types for a range of gas solubilities (11 species with effective Henry's law constant $H^{*}$ between 0 and $10^{9} \mathrm{~mol} \mathrm{dm}^{-3}$ $\mathrm{atm}^{-1}$ ). The simulations are listed in Table 1. Because we did not include concurrent gas phase chemical reactions in our model, all changes to the gas phase chemical species
Table 1. List of numerical experiments conducted for the continental (C1-C9) and maritime (M1-M9) cases. The burial coefficient, $\beta$, is the fraction of gas molecular collisions on a growing ice crystal that results in uptake. The retention coefficient, $R_{C}$, is the fraction of gas retained by a hydrometeor upon freezing. See Sect. 3.2 for more details.

\begin{tabular}{lcc}
\hline Runs & $\begin{array}{c}\text { Burial } \\
\text { Coefficient }(\beta)\end{array}$ & $\begin{array}{c}\text { Retention } \\
\text { Coefficient }\left(R_{C}\right)\end{array}$ \\
\hline C1, M1 & 0 & 1.0 \\
C2, M2 & 0 & 0.75 \\
C3, M3 & 0 & 0.5 \\
C4, M4 & 0 & 0.25 \\
C5, M5 & 0 & 0.0 \\
C6, M6 & 0.01 & 1.0 \\
C7, M7 & 0.1 & 1.0 \\
C8, M8 & 1.0 & 1.0 \\
C9, M9 & 0.1 & 0.0 \\
\hline
\end{tabular}

are induced by dynamical transport, dissolution, scavenging, or exclusion of chemical species due to freezing of drops. In addition, it should also be borne in mind that the simulated maritime cloud differs from the continental cloud only in terms of the initial CCN spectrum. Therefore, the 'continental'/'maritime' cloud in this study refers only to the cloud with the 'continental'/'maritime' CCN distribution.

\section{Results}

\subsection{Evolution of the cloud structure and precipitation}

Figure 3 shows the time evolution of the cloud physical properties (maximum values of water content, number concentrations of the different hydrometeors, vertical velocity, and rainfall rate). Figures 4 and 5 show the spatial distributions of wind field, water content and number concentration of each hydrometeor for the continental and maritime clouds. In both cases, the clouds begin to form after $8 \mathrm{~min}$ of simulation, and reach their peak updrafts 12 min later. While the maximum liquid water content (LWC), which mainly depends on the initial thermodynamic conditions, is similar in these two cases, the number concentration of drops as well as the properties of ice phase particles are quite different. The higher droplet concentration in the continental case leads to stronger competition for available water vapor during drop growth via diffusion and therefore restricts the size of cloud droplets. As a consequence, drop growth by the collision-coalescence process is less efficient in the continental case. In contrast, the droplets in the maritime cloud reach sizes required for efficient collision-coalescence comparably faster than those in the continental case. The differences in the evolution of water drops significantly influence characteristics of the ice phase hydrometeors. In the continental case, drops remain 

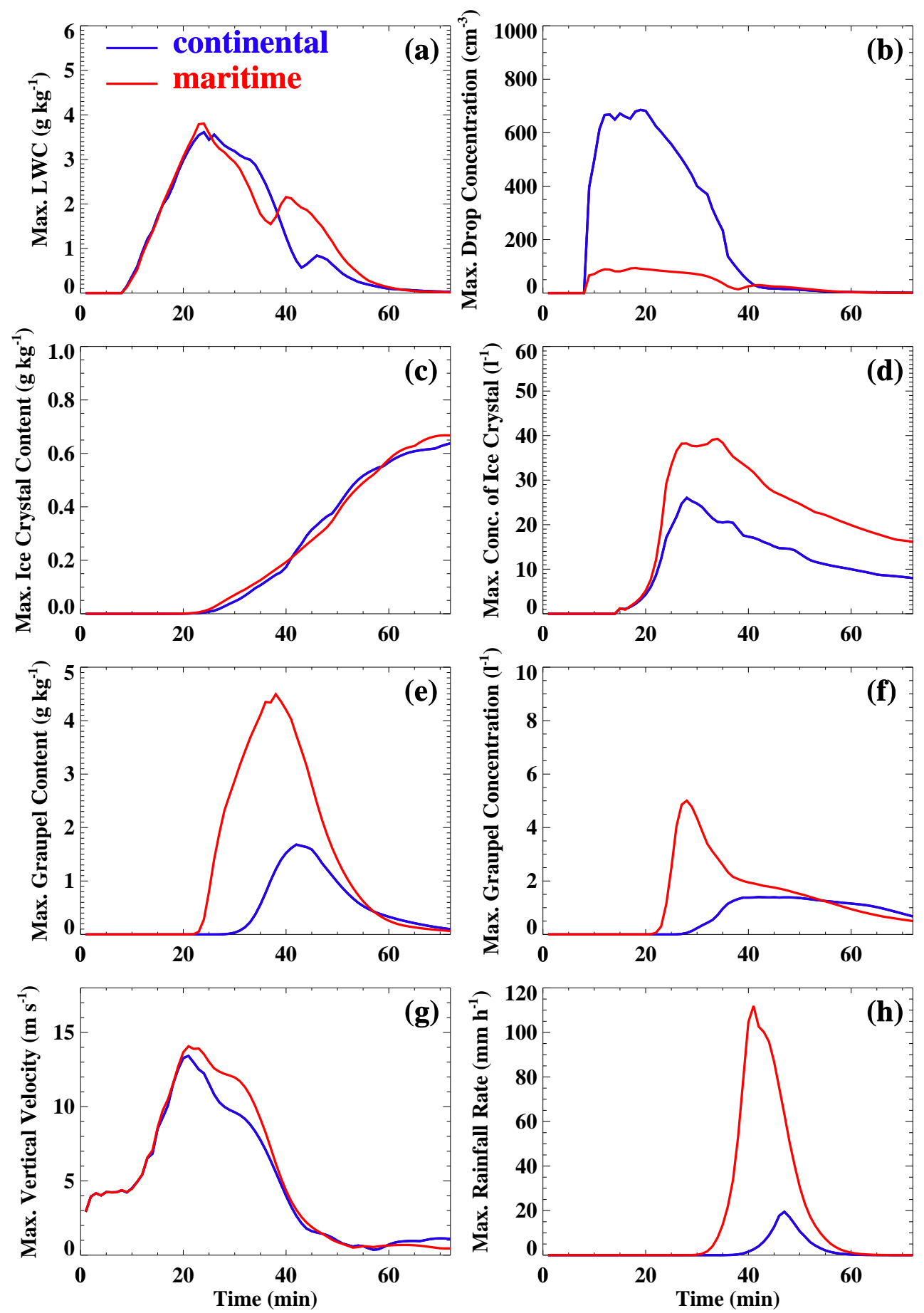

Fig. 3. Time-evolution of the maximum values of (a) liquid water content (LWC), (b) number concentration of drops, (c) water content of ice crystals, (d) number concentration of ice crystals, (e) water content of graupel particles, (f) number concentration of graupel particles, (g) vertical velocity, and (h) rainfall rate in the continental (blue curves), and maritime (red curves) cases.

small when they are lifted to the freezing level, and therefore, more drops are frozen to small graupel particles and ice crystals (in the model frozen drops are transferred to ice crystals if their radii are smaller than $100 \mu \mathrm{m}$, otherwise, they are transferred to graupel particles). On the other hand, the mar- itime case produces more larger graupel particles because of the larger drop sizes and thus promotes the collection process, leading to more rapid depletion of the droplets and to a higher supersaturation. This in turn promotes ice formation through vapor deposition and condensation-freezing, and can 

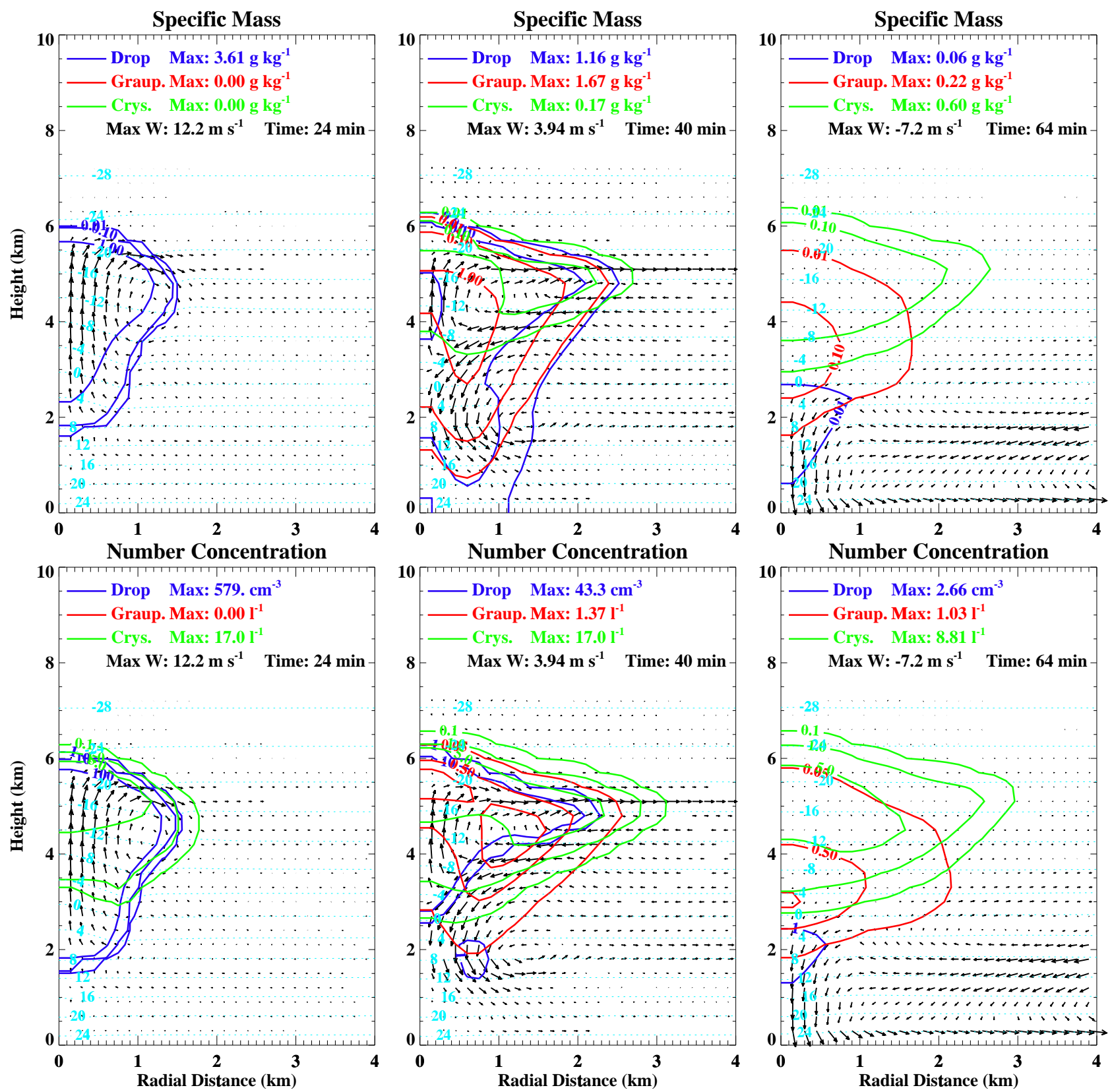

Fig. 4. Spatial distributions of specific mass (top panels) and number concentration (bottom panels) for drops, graupel and ice crystals in the continental simulation at "Cumulus stage" (at $24 \mathrm{~min}$ ) characterised by an updraft throughout most of the cell, "Mature stage" (at $40 \mathrm{~min}$ ) characterised by the presence of downdrafts and updrafts, and "Dissipation stage" (at 64 min) characterised by the weak downdrafts throughout most of the cell. The horizontal dotted lines are isotherms and arrows are wind vectors.

be seen from the time evolution of the production of ice crystals in Figs. 3d, e, and f, and Fig. 5.

The different liquid- and ice-phase microphysical processes in the two clouds are responsible for the reduced production of precipitation particles in the continental cloud compared with the maritime one (see Fig. 3h). Rain initiation and maximum rainfall rate are also 5-7 min later in the continental case than in the maritime case. The maximum accumulated rain in the maritime cloud is $16 \mathrm{~mm}$ and is only
$2.2 \mathrm{~mm}$ in the continental case. In both cases rain ended after around $64 \mathrm{~min}$ of simulation (here defined as rainfall rate less than $0.1 \mathrm{~mm}$ per hour). Such differences in the development of hydrometeors and precipitation have an important influence on the efficiency of gas transport to the upper troposphere as well as that of removal by wet deposition (wet deposition is calculated according to the fall velocities of the parent hydrometeors). This will be discussed in following sections. 

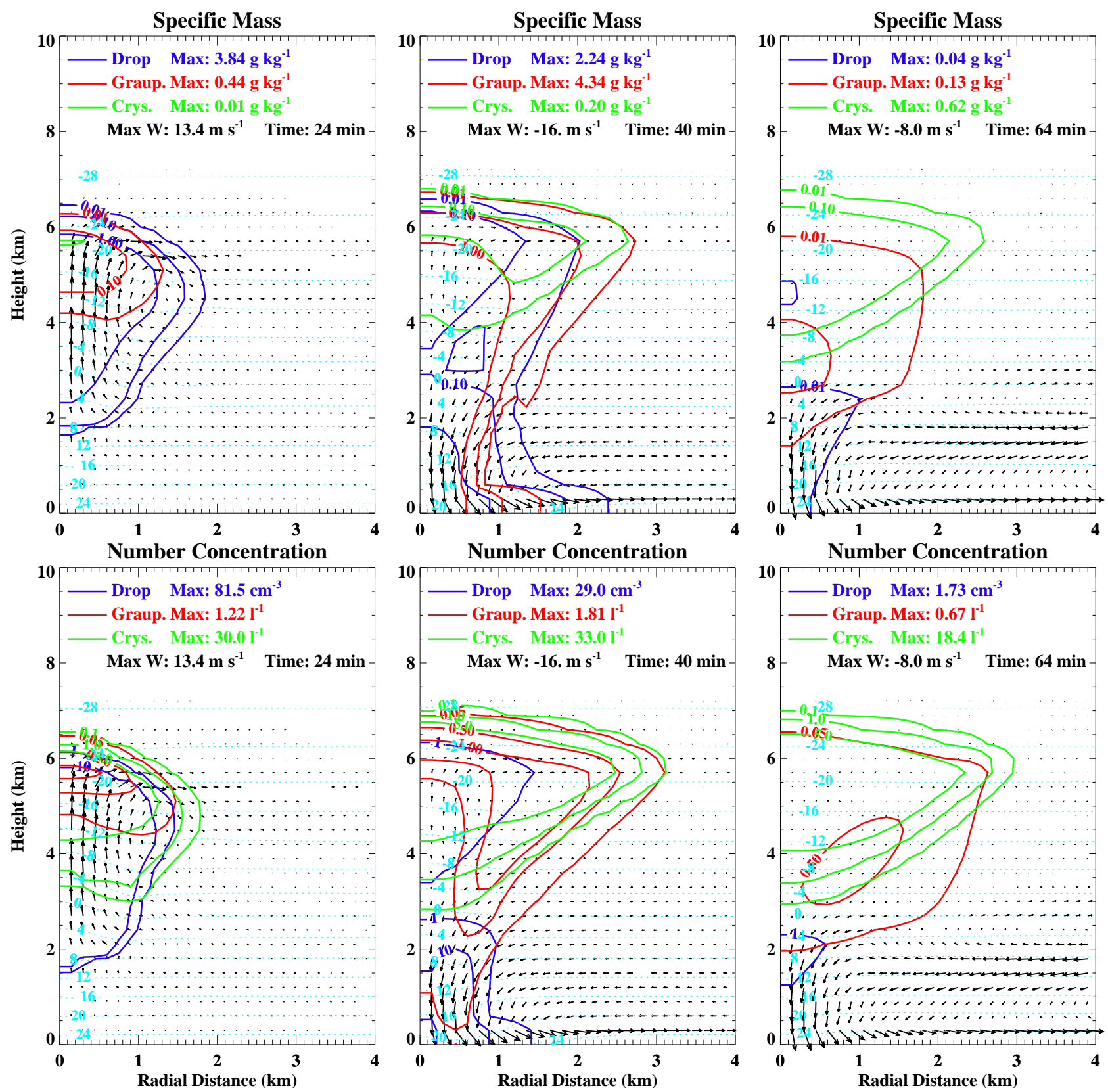

Fig. 5. Spatial distributions of specific mass (top panels) and number concentration (bottom panels) for drops, graupel and ice crystals in the maritime simulation at "Cumulus stage" (at $24 \mathrm{~min}$ ) characterised by an updraft throughout most of the cell, "Mature stage" (at $40 \mathrm{~min}$ ) characterised by the presence of downdrafts and updrafts, and "Dissipation stage" (at $64 \mathrm{~min}$ ) characterised by the weak downdrafts throughout most of the cell. The horizontal dotted lines are isotherms and arrows are wind vectors.

\subsection{The effect of retention coefficient on gas redistribution}

Figure 6 shows how the total gas transport depends on the gas solubility $\left(H^{*}\right)$ and retention coefficient $\left(R_{c}\right)$. The results are presented as integrated total species masses (gas plus all hydrometeor phases) over the entire cloud outflow region, which is all air above $4 \mathrm{~km}$ altitude (a gas molar mass of $50 \mathrm{~g}$ $\mathrm{mol}^{-1}$ is assumed, though absolute gas amounts are not as important as relative amounts). The results are shown for the maritime and continental clouds at $64 \mathrm{~min}$, which is after rainfall has ceased. As an example of one particular point on these contour plots, Fig. 7 shows the time evolution of gas abundance in different hydrometeors for $H^{*}=10^{7} \mathrm{~mol} \mathrm{dm}^{-3}$ $\mathrm{atm}^{-1}$ and $R_{c}=1$. In the following discussion we examine the effect of changes in $R_{c}$ and $H^{*}$ on gas transport in the maritime case and then compare the maritime and continental cases.

Gas solubility in liquid hydrometeors and gas retention 

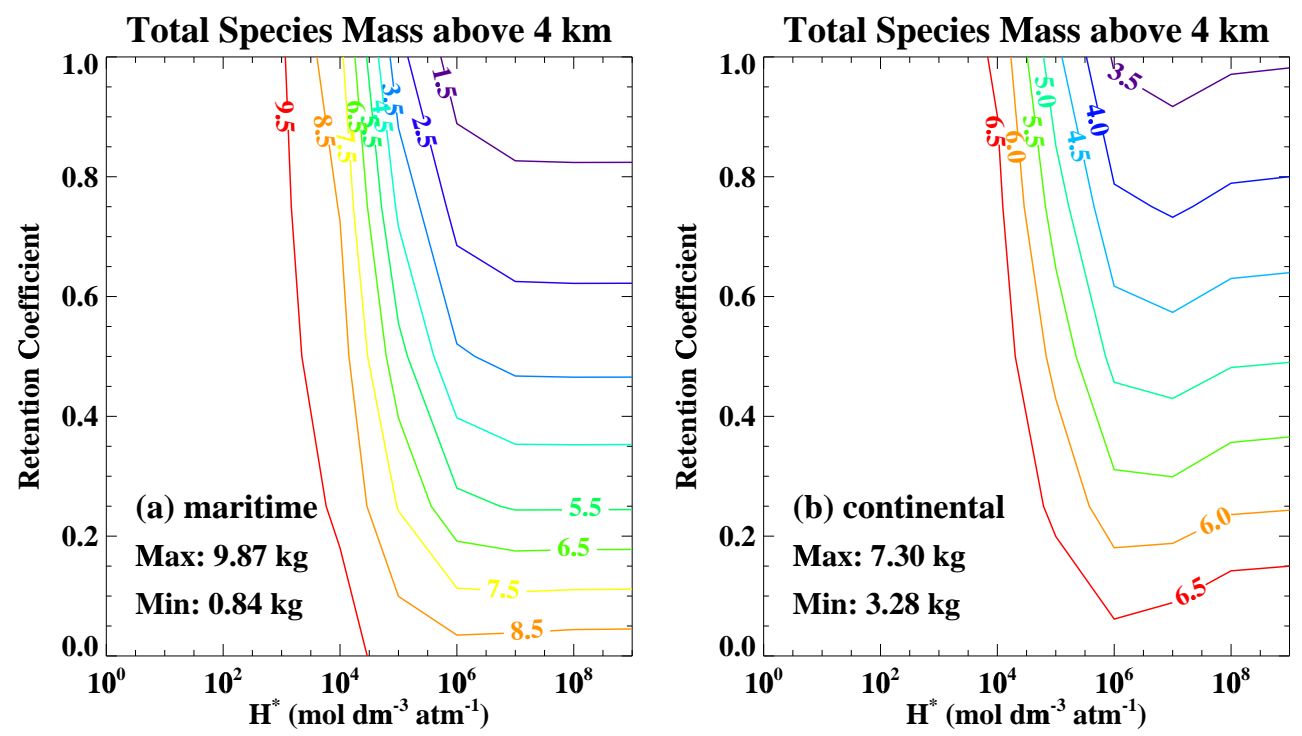

Fig. 6. Spatially integrated total species masses (gas plus all hydrometeor phases) above $4 \mathrm{~km}$ (the main cloud outflow region) as a function of gas solubility and retention coefficient after $64 \mathrm{~min}$ of simulation of (a) the maritime case and (b) the continental case. The gas burial coefficient $\beta=0$.

Table 2. Integrated trace gas mass (kg) removed by wet deposition in the continental (C1-C9) and maritime (M1-M9) clouds. Only results for gases with effective Henry's law constants of $0,10^{4}$, and $10^{7} \mathrm{~mol} \mathrm{dm}^{-3} \mathrm{~atm}^{-1}$, representative of insoluble, moderately soluble, and highly soluble gases, respectively, are shown here. Detailed definitions of these cases are given in Table 1.

\begin{tabular}{cccc|cccc}
\hline Runs & $H^{*}=0$ & $10^{4}$ & $10^{7}$ & Runs & $H^{*}=0$ & $10^{4}$ & $10^{7}$ \\
\hline C1 & 0.0 & 0.69 & 1.81 & M1 & 0.0 & 3.30 & 10.22 \\
C2 & 0.0 & 0.66 & 1.67 & M2 & 0.0 & 2.88 & 9.32 \\
C3 & 0.0 & 0.63 & 1.55 & M3 & 0.0 & 2.57 & 8.30 \\
C4 & 0.0 & 0.61 & 1.43 & M4 & 0.0 & 2.31 & 7.05 \\
C5 & 0.0 & 0.59 & 1.31 & M5 & 0.0 & 2.11 & 5.48 \\
C6 & 0.02 & 0.79 & 1.83 & M6 & 0.33 & 4.06 & 10.14 \\
C7 & 0.02 & 0.79 & 1.85 & M7 & 0.33 & 4.05 & 10.36 \\
C8 & 0.02 & 0.79 & 1.86 & M8 & 0.33 & 4.05 & 10.44 \\
C9 & 0.02 & 0.68 & 1.36 & M9 & 0.26 & 2.83 & 5.80 \\
\hline
\end{tabular}

upon freezing both lead to a decrease in total gas mass in the outflow region (Fig. 6a). However, the effect of changes in one of these quantities depends on the value chosen for the other. For $R_{c}=0$, changes in gas solubility $\left(H^{*}\right)$ have very little effect on gas transport. In this case, the transport of even highly soluble gases is similar to that of insoluble gases because gas expulsion from ice hydrometeors means that in large parts of the cloud the gas is present largely in the gas phase. (It should be noted that after expulsion from the ice, the gas dissolves into the remaining supercooled drops. This happens during most of the cloud lifetime and has been indicated in the previous study of Barth et al. (2001) (see their Fig. 11). But after 64 min, as can be seen in Figs. 4 and 5, there is very little liquid water left in the region above $4 \mathrm{~km}$, therefore, most of the tracer expelled from ice particles is present in the gas phase.)
The sensitivity of gas transport to $H^{*}$ increases as $R_{c}$ increases. For $100 \%$ gas retention upon freezing $\left(R_{c}=1\right)$, the gas mass in the outflow region is a factor 12 lower for a highly soluble gas than for an insoluble gas in the maritime cloud.

Changes in $R_{c}$ have little effect on the transport of low and moderately soluble gases but have a significant effect on the transport of highly soluble gases. For example, for $H^{*}=10^{4}$ mol dm ${ }^{-3}$ atm $^{-1}$ increasing $R_{c}$ from 0 to 1 leads to only a $20 \%$ decrease in gas transport but for $H^{*}>10^{6}$ gas transport decreases by a factor of 10 . The effect of changes in $R_{c}$ are approximately the same for all gas solubilities greater than $10^{6} \mathrm{~mol} \mathrm{dm}^{-3} \mathrm{~atm}^{-1}$ because this value of $H^{*}$ represents complete partitioning into the liquid phase before ice formation.

The continental clouds (Fig. 6b) show much less sensitiv- 

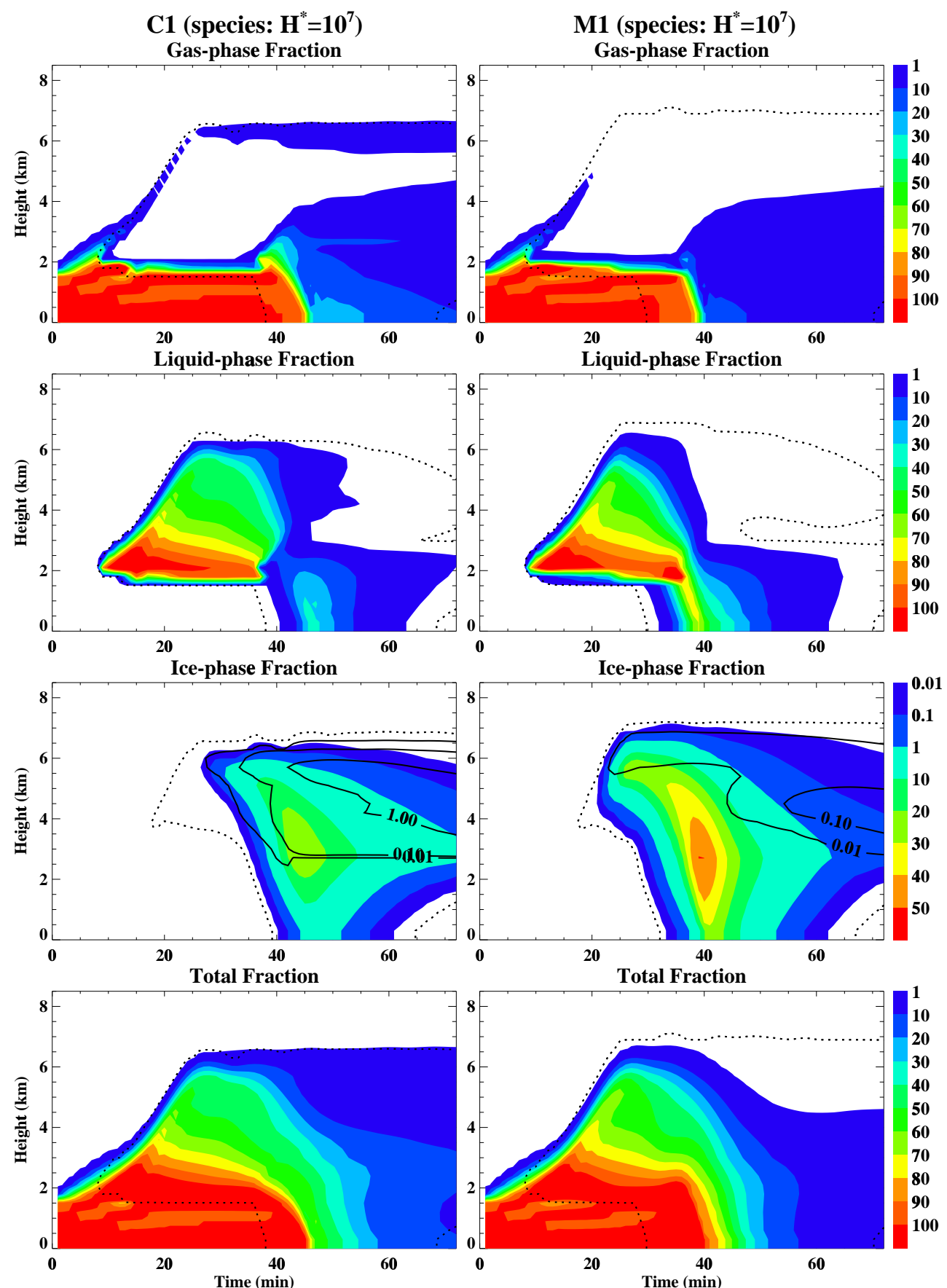

Fig. 7. Time-evolution of a soluble tracer $\left(H^{*}=10^{7} \mathrm{~mol} \mathrm{dm}^{-3} \mathrm{~atm}^{-1}\right)$ in the main updraft core (center of the cloud) of the continental cloud (left column) and maritime cloud (right column) with gas burial coefficient $\beta=0$ and retention coefficient $R_{C}=1$ (cases $\mathrm{C} 1$ and M1). The species abundance is expressed as percentages of the initial boundary layer mixing ratio. The tracer abundance in ice crystals (black solid contours) is over-plotted on that in graupel (filled colour contours). The black dotted lines are isolines of $10^{-3} \mathrm{~g} \mathrm{~kg}^{-1}$ condensed water for liquid-phase, ice-phase, and total water content.

ity to changes in $R_{c}$ and $H^{*}$ than the maritime clouds. For example, for highly soluble gases $\left(H^{*}>10^{6} \mathrm{~mol} \mathrm{dm}^{-3} \mathrm{~atm}^{-1}\right)$ a change in $R_{c}$ from 0 to 1 leads to a factor 10 decrease in gas transport for the maritime cloud but only a factor 2 decrease for the continental cloud. Also, for $R_{c}=1$, the decrease in gas transport for a highly soluble gas compared with an insoluble gas is a factor of 12 for the maritime cloud but only a factor of 2 for the continental cloud.

The much greater sensitivity of gas transport to gas solubility and retention for the maritime cloud compared with 

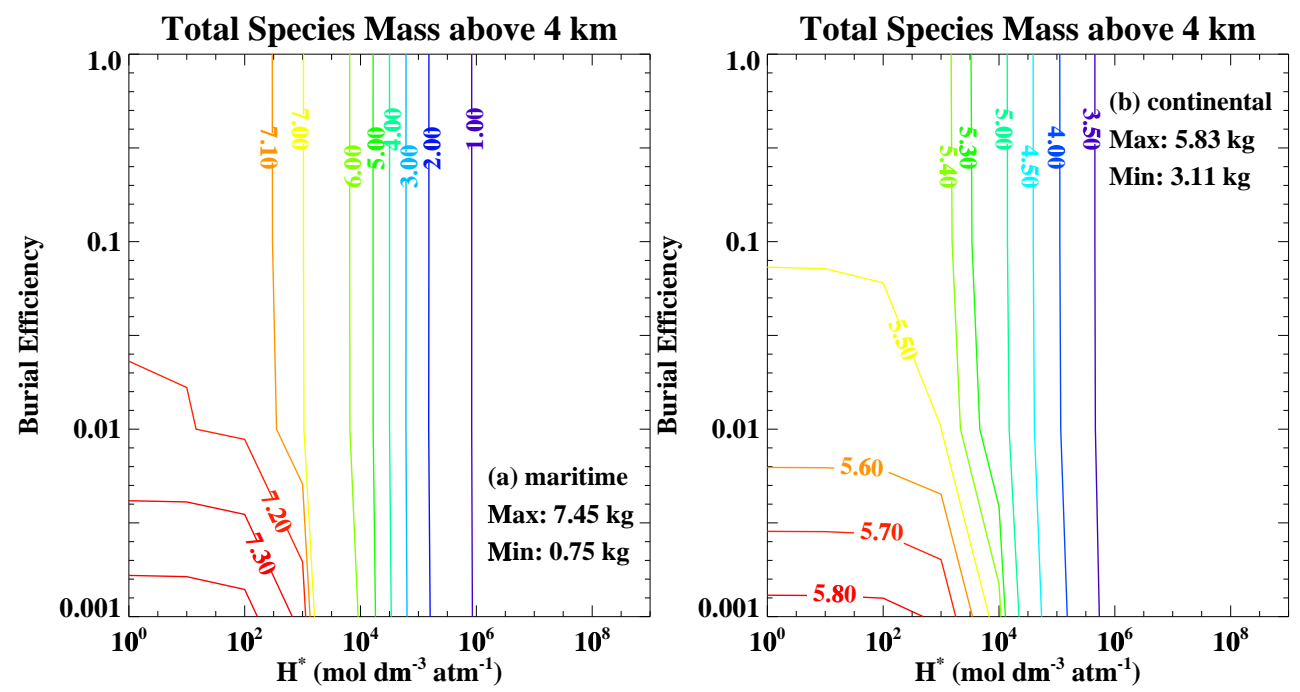

Fig. 8. Spatially integrated total species masses (gas plus all hydrometeor phases) above $4 \mathrm{~km}$ (the main cloud outflow region) as a function of gas solubility and burial coefficient after $64 \mathrm{~min}$ of simulation of (a) the maritime case and (b) the continental case. The gas retention coefficient $R_{C}=1$.

the continental cloud reflects differences in the microphysical processes, and in particular development of precipitation particles (Fig. 7). The main difference between the maritime and continental simulations is apparent in the trace gas abundance in the ice crystals and graupel particles: much more of the gas is present in graupel particles in the maritime case, which is consistent with the much higher graupel mass (see Sect. 4.1). The much more efficient precipitation processes occurring in the maritime cloud lead to efficient removal of the gas retained in large hydrometeors, and account for the large sensitivity of gas vertical transport to the choice of $R_{c}$ and $H^{*}$. The higher efficiency of precipitation formation in the maritime cloud is also reflected in the amount of gas washed out (Table 2).

Closer inspection of the model data also shows that in the continental case the slight increase in integrated trace gas masses for gas solubility higher than $10^{7} \mathrm{~mol} \mathrm{dm} \mathrm{dm}^{-3} \mathrm{~atm}^{-1}$ results from both gas and condensed phase material in the upper cloud layers. With an increase in gas solubility, more dissolved gas left in the condensed phase remains in the outflow region even after rain. We speculate that this accounts for the difference in characteristics from the maritime case in which most of the dissolved gas in the condensed phase is washed out.

4.3 The effect of gas scavenging by ice particles on gas redistribution

Gas scavenging here means the uptake and burial of trace gases by growing ice particles, and their release only upon ice particle evaporation or sublimation and is distinct from gas retention upon freezing, as discussed in the previous section.

Similar to Fig. 6, Fig. 8 shows the variation with gas sol- ubility and burial coefficient of the integrated total species masses (gas plus all hydrometeor phases) above $4 \mathrm{~km}$ altitude over the entire cloud outflow region. The results are shown for the maritime and continental clouds at $64 \mathrm{~min}$, and the retention coefficient $\left(R_{c}\right)$ in both figures is 1 . These figures indicate that the efficiency of gas scavenging has little effect on gas transport except for relatively insoluble gases. For soluble gases, transport is dominated by uptake into droplets, for which gas retention upon freezing is then the determining factor. This is generally consistent with the field measurements by Voisin et al. (2000) and can be explained by the fact that high solubility species such as strong acids are mainly present in the aqueous phase when riming occurs. Insoluble gases, however, are present largely in the gas phase in the cloud core, so their transport depends on the assumed uptake efficiency into growing ice crystals. However, even with highly efficient uptake into ice crystals (burial efficiency, $\beta=1$ ) the effect on gas concentrations in the cloud outflow region is relatively small. For example, for a moderately soluble gas with $H^{*}=10^{4} \mathrm{~mol} \mathrm{dm}^{-3} \mathrm{~atm}^{-1}$, changing $\beta$ from 0 to 1 reduces the total gas abundance in the outflow region by only $30 \%$ (compared with a factor of 12 change caused by changing $R_{c}$ from 0 to 1 ).

Although the efficiency of gas uptake into growing crystals is not important for overall gas transport, it is important in determining the gas concentration in ice particles that may subsequently form cirrus clouds. Figure 9 shows the gas abundance in ice particles and graupel particles for cases $\mathrm{C} 1$ (with $\beta=0$ ) and $\mathrm{C} 8$ (with $\beta=1.0$ ). In each case $R_{c}=1.0$. Ice particles dominate the hydrometeor population at the top of the cloud outflow region (see Figs. 4 and 5) and changing $\beta$ from 0 to 1 increases the gas abundance in these ice particles by almost two orders of magnitude for the moderately 


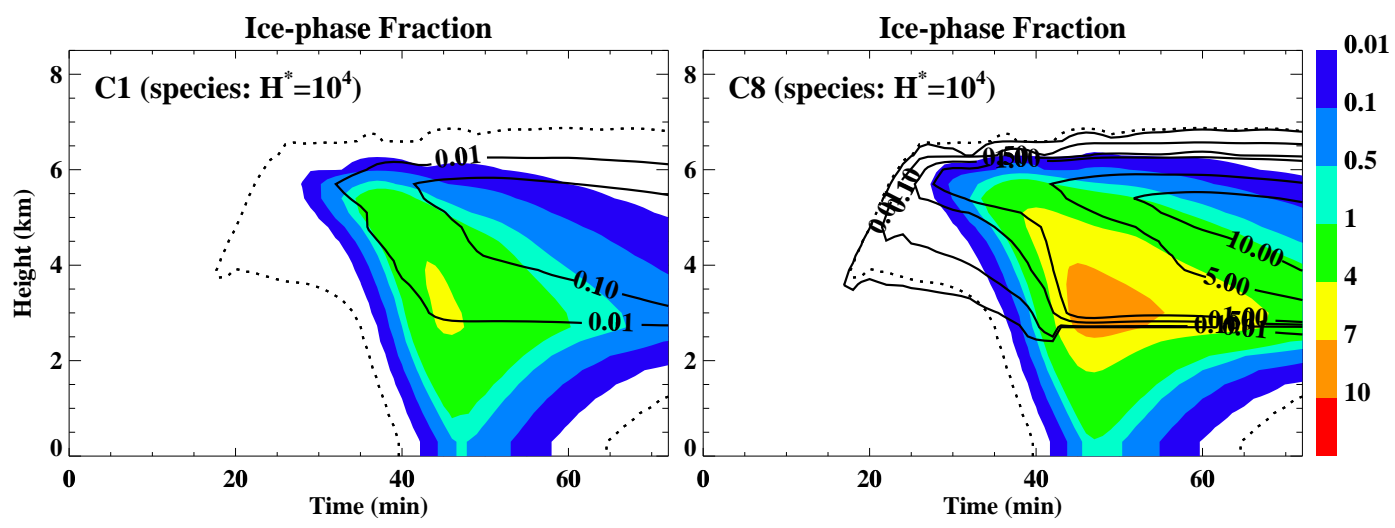

Fig. 9. The effect of gas burial in growing ice crystals on the abundance of a trace gas in ice crystals and graupel in a continental cloud. Results are shown as the time-evolution of a moderately soluble tracer $\left(H^{*}=10^{4} \mathrm{~mol} \mathrm{dm}^{-3} \mathrm{~atm}^{-1}\right)$ in the main updraft core (or at the center of the cloud) for gas burial coefficient $\beta=0$ (case $\mathrm{C} 1$, left column) and $\beta=1$ (case $\mathrm{C} 8$, right column). The species abundance is expressed as percentages of the initial boundary layer mixing ratio. The tracer abundance in ice crystals (black solid lines) is over-plotted on that in graupel (filled colour contours). The black dotted line is the isoline of ice-phase water content $=10^{-3} \mathrm{~g} \mathrm{~kg}^{-1}$. In both cases the gas retention coefficient $R_{c}=1$.
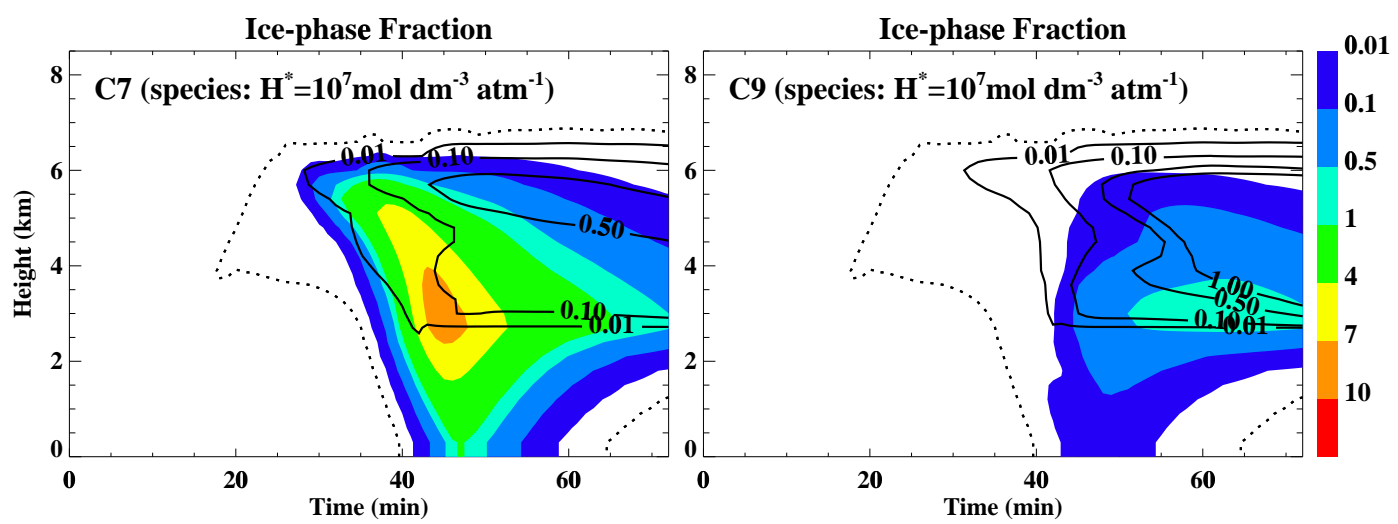

Fig. 10. The effect of gas retention coefficient on the abundance of soluble tracers in ice crystals and graupel in the continental case. Results are shown as the time-evolution of a highly soluble $\left(H^{*}=10^{7} \mathrm{~mol} \mathrm{dm}^{-3} \mathrm{~atm}^{-1}\right)$ tracer with moderate burial coefficient $(\beta=0.1)$ in the main updraft core (or at the center of the cloud) for retention coefficient $R_{c}=1$ (case $\mathrm{C} 7$, left column) and $R_{C}=0$ (case C9, right column). The species abundance is expressed as percentages of the initial boundary layer mixing ratio. The tracer abundance in ice crystals (black solid lines) is over-plotted on that in graupel (filled colour contours). The black dotted line is the isoline of ice-phase water content $=$ $10^{-3} \mathrm{~g} \mathrm{~kg}^{-1}$.

soluble gas $\left(H^{*}=10^{4} \mathrm{~mol} \mathrm{dm}^{-3} \mathrm{~atm}^{-1}\right)$. In contrast, the changes calculated for the highly soluble gas (not shown) are negligible. However, if the soluble tracer is degassed upon freezing (or $R_{c}=0$ ) and then scavenged by rapidly growing ice particles (high burial coefficient), then the gas abundance in ice crystals can be increased by a factor of 2 even for a highly soluble gas with $H^{*}=10^{7} \mathrm{~mol} \mathrm{dm}^{-3} \mathrm{~atm}^{-1}$ (Fig. 10). In this case the gas abundance in graupel is significantly reduced, especially for the highly soluble tracer.

It is also worth noting that while gas uptake by ice increases the abundance of that tracer in the ice phase, the amount deposited by precipitation on the surface remains essentially unchanged due to the fact that the low solubility tracers are released to the gas phase once their ice-phase carriers fall below the $0^{\circ} \mathrm{C}$ level and begin to melt (see Table 2).
It should be stressed that these simulations represent upper and lower limits to the likely partitioning of gases into growing ice crystals. It is unlikely that any gases will become buried in growing ice crystals with $100 \%$ efficiency. However, moderately soluble gases (in this case $H^{*}=10^{4} \mathrm{~mol}$ $\mathrm{dm}^{-3} \mathrm{~atm}^{-1}$ ) are likely to become buried in growing crystals to some extent, and in such cases accurate knowledge of burial efficiencies will be important.

\section{Conclusions}

The Yin et al. (2001) model has been extended to include ice phase microphysics and trace gas transport. In representing these processes we have reduced the problem, for a given 
cloud evolution, to a three-dimensional parameter space of gas solubility $\left(H^{*}\right)$, retention coefficient $\left(R_{c}\right)$, and burial efficiency $(\beta)$, acting to define the transport properties of a gas in a given cloud. The behaviour of the model as these parameters are varied has been explored for two idealised clouds maritime and continental - and in each case, the variation of transport with $H^{*}, R_{c}$ and $\beta$ has been quantified.

The results show that the magnitude of total gas amount transported to the upper troposphere is controlled by gas solubility and gas retention coefficient. Gas transport is most sensitive to the value of retention coefficient when the solubility is high and, similarly, is most sensitive to solubility for high retention coefficients. Knowledge of the gas retention coefficient is more important for maritime clouds than continental clouds, with a high retention coefficient leading to higher wet removal of soluble tracers, according to the rainfall rate in the cloud. In the extreme case with all the dissolved gas being released from liquid drops upon freezing $\left(R_{c}=0\right)$, even the highly soluble gases can be transported to the free atmosphere and upper troposphere. This is consistent with the results of Barth et al. (2001), although different thermodynamic conditions are used for intialization of the simulations.

We have found that the total gas transport is relatively insensitive to direct gas uptake by growing ice particles (the gas burial efficiency). However, the burial efficiency strongly controls the concentration of trace gases inside anvil ice crystals, which subsequently form cirrus clouds.

The results obtained with this cloud model are now quite exhaustive, in that they represent all the key transport processes. A number of other processes, notably reactive chemistry, are not yet described. It is important at this stage to test the model results against observational data.

Our results also indicate where gaps in our understanding of basic physical processes could impact our ability to predict gas transport in mixed-phase clouds. For example, defining the gas retention coefficient of a highly soluble gas $\left(H^{*}>10^{6} \mathrm{~mol} \mathrm{dm} \mathrm{atm}^{-1}\right)$ in the range $0.5-1.0$ allows the gas transport to be defined only to within a factor of 4 for a maritime cloud. However, for a moderately soluble gas $\left(H^{*} \sim 10^{4} \mathrm{~mol} \mathrm{dm}^{-3} \mathrm{~atm}^{-1}\right)$ the uncertainty in gas transport would be less than a factor of 2 .

We have also highlighted the need for a physical representation of gas uptake into ice hydrometeors that accounts for the rate at which the particles are growing.

Acknowledgements. This research was conducted within the project "Particles in the Upper Troposphere and Lower Stratosphere and Their Role in the Climate System" (PARTS) funded by the European Commission, and the Upper Troposphere - Lower Stratosphere (UTLS-Ozone) thematic programme funded by the U.K. Natural Environment Research Council (NERC). We thank Prof. Zev Levin for kindly allowing us to use the axisymmetric cloud model. The helpful comments given by Drs. M. Barth, C. Mari, and S. Kreidenweis are also highly appreciated.

\section{References}

Barth, M. C., Stuart, A. L., and Skamarock, W. C.: Numerical simulations of the July 10 Stratospheric-Tropospheric Experiment: Radiation, Aerosols, and Ozone/Deep Convection storm: Redistribution of soluble tracers, J. Geophys. Res., 106, $12381-$ 12400, 2001.

Chatfield, R. B., and Crutzen, P. J.: Sulfur dioxide in the remote oceanic air: Cloud transport of reactive precursors, J. Geophys. Res., 89, 7111-7132, 1984.

Clapsaddle, C. and Lamb, D.: Sorption behavior of $\mathrm{SO}_{2}$ on ice at temperature between $-30^{\circ} \mathrm{C}$ and $-5^{\circ} \mathrm{C}$, Geophys. Res. Lett., 16 , 1173-1176, 1989.

Clegg, S. M. and Abbatt J.P.D.: Uptake of gas-phase $\mathrm{SO}_{2}$ and $\mathrm{H}_{2} \mathrm{O}_{2}$ by ice surface: dependence on partial pressure, temperature, and surface acidity, J. Phys. Chem., 105, 6630-6636, 2001.

Conklin, M. H. and Bales, R. C.: $\mathrm{SO}_{2}$ uptake on ice sphere: Liquid nature of the ice-air interface, J. Geophys. Res., 98, 16844 $16851,1993$.

Conklin, M. H., Sommerfeld, R. A., Layrd, S. K., and Villinski, J. E.: Sulfur dioxide reactions on ice surface: implications for dry deposition to snow, J. Atmos. Environ., 27A, 159-166, 1993.

Crutzen, P. J. and Lawrence, M. G.: The impact of precipitation scavenging on the transport of trace gases: A 3-dimensional model sensitivity study, J. Atmos. Chem., 37, 81-112, 2000.

Dickerson, R. R., Huffman, G. J., Luke, W. T., et al.: Thunderstorms: An important mechanism in the transport of air pollutants, Science, 235, 460-465, 1987.

Diehl, K., Mitra, S. K., and Pruppacher, H. R.: A laboratory study of the uptake of $\mathrm{HNO}_{3}$ and $\mathrm{HCl}$ vapor by snow crystals and ice spheres at temperature between 0 and $-40^{\circ} \mathrm{C}$, Atmos. Environ., 29A, 975-981, 1995.

Diehl, K., Mitra, S. K., and Pruppacher, H. R.: A laboratory study on the uptake of $\mathrm{HCl}, \mathrm{HNO}_{3}$, and $\mathrm{SO}_{2}$ gas by ice crystals and the effect of these gases on the evaporation rate of the crystals, Atmos. Res., 47/48, 235-244, 1998.

Hudson, P. K., Foster, K. L., Tolbert, M. A., et al.: HBr uptake on ice: Uptake coefficient, $\mathrm{H}_{2} \mathrm{O} / \mathrm{HBr}$ hydrate formation, and $\mathrm{H}_{2} \mathrm{O}$ desorption kinetics, J. Phys. Chem., 105, 694-702, 2001.

Iribarne, J. V. and Pyshnov, T.: The effect of freezing on the composition of supercooled droplets - I. Retention of $\mathrm{HCl}, \mathrm{HNO}_{3}$, and $\mathrm{NH}_{3}$, J. Atmos. Environ., 24A, 383-387, 1990.

Iribarne, J. V., Pyshnov, T., and Naik, B.: The effect of freezing on the composition of supercooled droplets - II. Retention of $\mathrm{SO}_{2}$, J. Atmos. Environ., 24A, 389-395, 1990.

Lamb, D. and Blumenstein, R.: Measurement of the entrapment of sulfur dioxide by rime ice, Atmos. Environ., 21, 1765-1772, 1987.

Mari, C., Jacob, D. J., and Bechtold, P.: Transport and scavenging of soluble gases in a deep convective cloud, J. Geophys. Res., 105, 22 255-22 267, 2000.

Mitra, S. K., Barth, S., and Pruppacher, H. R.: A laboratory study on the scavenging of $\mathrm{SO}_{2}$ by snow crystals, Atmos. Environ., 24A, 2307-2312, 1990.

Prather, M. J. and Jacob, D. J.: A persistent imbalance in $\mathrm{HO}_{x}$ and $\mathrm{NO}_{x}$ photochemistry of the upper troposphere driven by deep tropical convection, Geophys. Res. Lett., 24, 3189-3192, 1997.

Pruppacher, H. R. and Klett, J. D.: Microphysics of Clouds and Precipitation, D. Reidel, pp. 714, 1997. 
Reisin, T., Levin, Z., and Tzivion, S.: Rain production in convective clouds as simulated in an axisymmetric model with detailed microphysics. Part I: Description of the model, J. Atmos. Sci., 53, 497-519, 1996.

Santachiara, G., Frodi, F., and Vivarelli, F.: Scavenging of $\mathrm{SO}_{2}$ and $\mathrm{HCl}$ during growth of ice crystals by vapour diffusion, Atmos. Environ., 29, 983-987, 1995.

Snider, J. R., Montague, D. C., and Vali, G.: hydrogen peroxide retention in rime ice, J. Geophys. Res., 97, 7569-7578, 1992.

Sommerfeld, R. A. and Lamb, D.: Preliminary measurements of $\mathrm{SO}_{2}$ adsorbed on ice, Geophys. Res. Lett., 13, 349-351, 1986.

Tzivion, S., Feingold, G., and Levin, Z.: A efficient numerical solution to the stochastic collection equation, J. Atmos. Sci., 44, 3139-3149, 1987.

Valdez, M. P., Dawson, G. A., and Bales, R. C.: Sulfur dioxide incorporation into ice depositing from the vapor, J. Geophys. Res.,
94, 1095-1103, 1989.

Voisin, D., Legrand, M., and Chaumerliac, N.: Scavenging of acidic gases $\left(\mathrm{HCOOH}, \mathrm{CH}_{3} \mathrm{COOH}, \mathrm{HNO}_{3}, \mathrm{HCl}\right.$, and $\left.\mathrm{SO}_{2}\right)$ and ammonia in mixed liquid-solid water clouds at the puy de Dome mountain (France), J. Geophys. Res., 105, 6817-6835, 2000.

Yin, Y., Levin, Z., Reisin, T. G., and Tzivion, S.: The effects of giant cloud condensation nuclei on the development of precipitation in convective clouds - A numerical study, Atmos. Res., 53, 91-116, 2000.

Yin, Y., Parker, D. J., and Carslaw, K. S.: Simulation of trace gas redistribution by convective clouds - Liquid phase processes, Atmos. Chem. Phys., 1, 19-36, 2001.

Zondlo, M. A., Barone, S. B., and Tolbert, M. A.: Uptake of $\mathrm{HNO}_{3}$ on ice under upper tropospheric conditions, Geophys. Res. Lett., 24, 1391-1394, 1997. 